
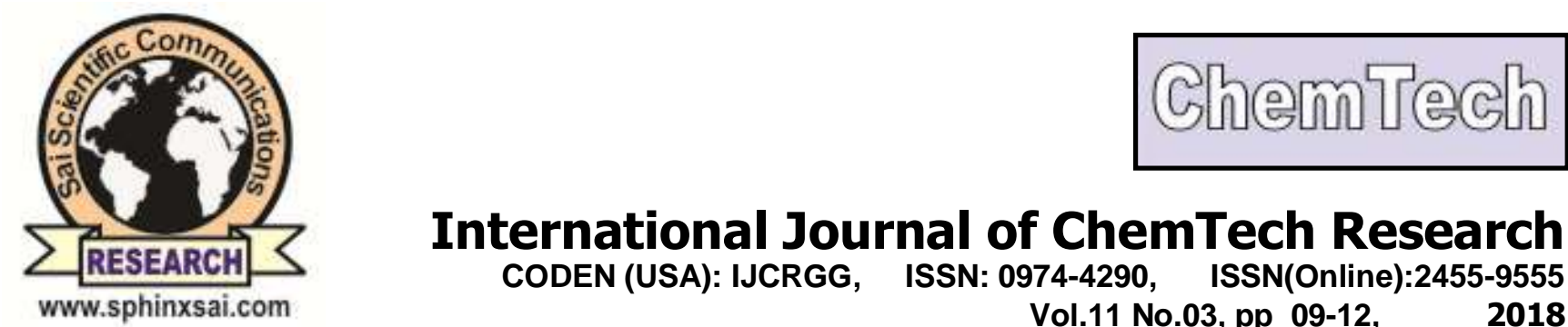

International Journal of ChemTech Research CODEN (USA): IJCRGG, ISSN: 0974-4290, ISSN(Online):2455-9555

Vol.11 No.03, pp 09-12, 2018

\title{
The Pattern of Antifungal Resistance against Candida albicans that cause Vaginal Candidiasis
}

\author{
${ }^{*}$ Riana Miranda Sinaga, Flora Marlita Lubis, Dian Dwi Wahyuni \\ Departement of Dermatology and Venereology Faculty of Medicine, Universitas \\ Sumatera Utara, Indonesia
}

\begin{abstract}
Background: Vaginal candidiasis is a vaginal infection caused by Candida albicans or other Candida species. Recent epidemiological data suggest an increase in infections caused by resistant fungal species, especially the fluconazole-resistant Candida species.

Objective : To find out how the pattern of antifungal resistance to Candida albicans causes vaginal candidiasis and characteristic features of vaginal candidiasis.

Methods: This is an observational descriptive study with cross sectional design. Samples were obtained from patients with vaginal candidiasis who met the inclusion and exclusion criteria at Sentosa Baru Public Health Center from August to November 2017.

Results: There were 20 samples isolated from specimens of vaginal secretion of vaginal candidiasis patients. From the identification result, 14 samples (70\%) of Candida albicans causing vaginal candidiasis were resistant to Itraconazole and Fluconazole, followed by Amphotericin B dan Variconazole (65\%). However 17 samples (85\%) of Candida albicans causing vaginal candidiasis were still sensitive to Flucytosin. From the data collected, it was found that vaginal candidiasis patients caused by Candida albicans were found in patients age $30-35$ years old $(50 \%)$, working as housewife $(65 \%)$, with last education of high school $(60 \%)$.

Conclusion : drug resistance to antifungal against Candida albicans causes vaginal candidiasis has been found.
\end{abstract}

Keywords : resistance pattern, characteristics, Candida albicans, vaginal candidiasis, antifungal.

\section{Introduction}

Vaginal candidiasis is a vaginal infection caused by Candida albicans or other Candida species. More than $90 \%$ of vaginal candidiasis infections are caused by Candida albicans. $75 \%$ of women at least once in their lives infected by Vaginal candidiasis. This infection may occur acute, subacute and chronic, both endogenous and exogenous which often leads to vaginal discharge. ${ }^{1}$

Recent epidemiological data suggest an increase in infections caused by resistant fungal species, especially the fluconazole-resistant Candida species. In addition, the fungus previously thought to be

International Journal of ChemTech Research, 2018,11(03): 09-12.

DOI : http://dx.doi.org/10.20902/IJCTR.2018.110302 
contaminant, was resistant to all available antifungal drugs, even caused an invasive and life-threatening infections so-called emerging fungi. ${ }^{2}$

Research on the sensitivity of azole drug classes against Candida in the Micology Laboratory Department of Parasitology FKUI has been published by Rozaliyani and Erwin. The examination of the antifungal resistance test in vitro uses clinical materials derived from patients who are sent by practicing physicians, other laboratories and from various hospitals. Research by Rozaliyani in neonates with kandidemia reported a lower prevalence of resistance to fluconazole (3.8\%) than itraconazole (9.6\%). The study by Erwin showed the prevalence of resistance between fliconazole and voriconazole was not significantly different. ${ }^{3}$

Based on study made by Sekaran at Pancur Batu Community Health Center in 2016, 44\% pstients of vulvovaginal candidiasis most occur in age group $30-39 .{ }^{4}$

The expand of vaginal candidiasis infection and fewer available therapeutic options, antifungal resistance can be a serious problem in the future. The determination of in vitro susceptibility to antifungal is lagging behind antibacterial drugs, mainly due to variations between laboratories and lack of standardized suseptibility examination. Understanding antifungal drug resistance is essential for developing effective prophylactic and treatment strategies in order to avoid problems caused by resistant fungi. ${ }^{5}$

\section{Patient and Methods}

This is an observational descriptive study with cross sectional design. Samples were obtained from patients with vaginal candidiasis who met the inclusion and exclusion criteria at Sentosa Baru Public Health Center from August to November 2017. Sampling of vaginal discharge was performed on patients diagnosed with vaginal candidiasis based on anamnesis and clinical symptoms were obtained 20 samples suffering from vaginal candidiasis caused by Candida albicans based on the identification of candida through gram staining and culture specimen. Then on 20 samples obtained were tested sensitivity to antifungal drugs.

\section{Result and Discussion}

From 20 samples were tested for sensitivity of antifungal drugs. Researchers also took data about age, level of education and work that can be seen in tables below.

Table 1. The frequency distribution of vaginal candidiasis patient caused by Candida albicans based on age

\begin{tabular}{|l|l|l|}
\hline Age (year) & Frequency & Presentage $(\%)$ \\
\hline $30-35$ & 10 & 25.0 \\
\hline $36-40$ & 5 & 50.0 \\
\hline $41-45$ & 3 & 15.0 \\
\hline $46-50$ & 2 & 10.0 \\
\hline Total & 20 & 100.0 \\
\hline
\end{tabular}

Based on the table above it is known that from 20 patients who experience vaginal candidiasis caused by most occur in the age group 30-35 years is 50\% and least occur in the age group 46-50 years about $10 \%$. Based on the prevalence of Candida species is highly significant in the age group of 26-35 years compared to other age groups. ${ }^{6}$

Table 2. The frequency distribution of vaginal candidiasis patients caused by Candida albicans based on education level

\begin{tabular}{|l|l|l|}
\hline Education Level & Frequency & Persentage (\%) \\
\hline Junior High School & 5 & 25.0 \\
\hline Senior High School & 12 & 60.0 \\
\hline $\begin{array}{l}\text { Diploma/Bachelor } \\
\text { (D3,S1) }\end{array}$ & 3 & 15.0 \\
\hline Total & 20 & 100.0 \\
\hline
\end{tabular}


From the table above showed that more than half patient with vaginal candidiasis caused by candida albicans had educational level as Senior High School (60\%), followed by Junior high school (25\%) and Collage educational level (15\%).

Study by Reed, et.al (2003) suggests vulvovaginal candidiasis is associated with an education level of more than 12 years or who has graduated from high school or in high school. ${ }^{7}$

The level of education is related to the perception of the patient about the disease, so that the patient is more understand and immediately check themselves when the complaint of vaginal candidiasis arises.

Table 3 The frequency distribution of vaginal candidiasis patients caused by Candida albicans based on job

\begin{tabular}{|l|l|l|}
\hline Job & Frequency & Percentage (\%) \\
\hline Entrepreneur & 4 & 20.0 \\
\hline private employees & 2 & 10.0 \\
\hline Teacher & 1 & 5.0 \\
\hline Housewife & 13 & 65.0 \\
\hline Total & 20 & 100.0 \\
\hline
\end{tabular}

From the table above it was found that more than half of patients with vaginal candidiasis caused by Candidia albicans, $65 \%$ occurred in women who did not work. Less appear in women who work as teachers that is 5\%. According to research Minarni LD (2003) said the incidence of vulvovagina candidiasis most in women with the work of housewives. ${ }^{8}$

Tabel 4. Sensitivity pattern of Candida albicans causes of vaginal candidiasis with anti- Fungal drugs

\begin{tabular}{|l|ll|ll|l|r|}
\hline \multicolumn{1}{|c|}{ Anti-fungal drugs } & \multicolumn{2}{|c|}{ Resistant } & \multicolumn{2}{c|}{ Sensitivity } & \multicolumn{2}{c|}{ Intermediate } \\
\hline & $(\mathrm{n}=20)$ & $\%$ & \multicolumn{2}{c|}{$(\mathrm{n}=20)$} & $\%$ & \multicolumn{2}{c|}{$(\mathrm{n}=20)$} & $\%$ \\
\hline Flucytosin & 0 & 0.0 & 17 & 85.0 & 3 & 15.0 \\
\hline Amphotericin B & 13 & 65.0 & 7 & 35.0 & 0 & 0.0 \\
\hline Fluconazole & 14 & 70.0 & 6 & 30.0 & 0 & 0.0 \\
\hline Itraconazole & 14 & 70.0 & 6 & 30.0 & 1 & 5.0 \\
\hline Variconazole & 13 & 65.0 & 6 & 30.0 & 0 & 0.0 \\
\hline
\end{tabular}

Based on the table above, it is known that from 20 patients who have vaginal candidiasis caused by candidia albicans resistant to fluconazole antifungal $(70 \%)$ and itraconazole $(70 \%)$ followed by resistance to drug Amphotericin B (65\%) and Variconazole (65\%), but not to Flucytosin. However, the antifungal drug Flucytosin is still sensitive to Candida albicans that causes vaginal candidiasis of $85 \%$

From Sobel's research, et al (2003) showed the success of topical therapy with topical flucytosine reached $90 \%$ from 27 vulvoginitis patients caused by Candida glabrata which had previously failed to be treated with azole and borax acid, and in vitro has been tested Flucytosin is superior to antifungal drugs other to Candida glabrata. ${ }^{9}$

Based on the study in the United States, it was said that fluconazole resistance occurred in $14(3.6 \%)$ samples of Candida albicans that caused vaginal candidiasis from 393 samples in 2001. In New York 2 (2.1\%) of 93 samples of Candida albicans in the vagina found that resisten to fluconazole. ${ }^{9}$

\section{Conclusion}

Research on the pattern of antifungal resistance against Candida albicans that cause vaginal candidiasis has been found. From 20 samples were tested sensitivity to antifungal drugs. Conclusions of the study have found resistance of antifungal drugs to Candida albicans causes vaginal candidiasis, namely: fluconazole (70\%) and itraconazole (70\%) antifungal drugs followed by resistance to Amphotericin B (65\%) and Variconazole 
(65\%), but no resistance to the anti-fungal drug Flucytosin $(0 \%)$ was found. However, the antifungal drug Flucytosin is still sensitive to Candida albicans that causes vaginal candidiasis as high as $85 \%$.

\section{References}

1. Nabhan, A. 2006. Vulvovaginal Candidiasis. ASJOG, 3:73-79.

2. Apsari, A.S., Adiguna M.S. 2013. Resistensi Antijamur dan Strategi untuk Mengatasi. MDVI, 40(2):89-95.

3. Yogo, M., Ridhawati. 2013. Pola Kepekaam Candida albicans Terhadap Flukonazol dan Itrakonazol secara In Vitro : Tinjauan pada Bahan Klinik Laboratorium Mikologi Departemen Parasitologi FKUI Periode 2010-2011. Jakarta, Universitas Indonesia. Thesis.

4. Sekaran. 2016. Profil penderita kandidiasis vulvovaginal di Puskesmas Pancur Batu tahun 2016. repository.usu.ac.id

5. Sanglard, D., Odds, F.C. 2002. Resistance of Candida species to Antifungal Agents : Molecular Mechanisms and Clinical Consequences. The Lancet Infectious Diseases, 2:73-85.

6. Akortha E.E, Nwaugo V.O,Chikwe N.O.2009 Antifungal resistance among Candida species from patient with genitourinary tract infection isolated in Benin City, Edo state, Nigeria. African Journal of Microbilogy Research 3(11):694:699

7. Reed BD, Zazove P, Pierson CL, Gorenflo D, et al. Candida transmission and sexual behaviors as risk for a repeat episode of Candida vulvovaginitis. 2003. Journal of women's health., 12: 3: 979-989

8. Minarni LD. Perbandingan morfologi mikroskopis Candida albicans pada penderita KVV simptomatis dan asimptomatis. Tesis, 2003.

9. Richter S.S, Galask R.P, Messer S.A, Hollis R.J, Diekema D.J, Pfaller M.A. 2005. Antifungal Susceptibilities of Candida Species Causing Vulvovaginitis and Epidemiology of Recurrent Cases. Journal of Clinical Microbiology. Doi:10.11.1128/JCM.43.5.2155-2162.2005. 